\title{
Efeito do Diagnóstico de Câncer e Sugestões para Comunicação Diagnóstica na Visão dos Pacientes
}

https://doi.org/10.32635/2176-9745.RBC.2018v64n4.197

\author{
Effect of Cancer Diagnosis and Suggestions for Diagnostic Communication in Patient Vision \\ Efecto del Diagnóstico de Cáncer y Sugerencias para Comunicación Diagnóstica en la Visión de los Pacientes
}

\author{
Alessandra da Cunha Neumayer'; Márcia Cristina Maciel de Aguiar²; Eldsamira da Silva Mascarenhas Schettini Sobrinho³; Alinne \\ Santiago Ramos Gonçalves ${ }^{4}$
}

\section{Resumo}

Introduçáo: $\mathrm{O}$ câncer é classificado como uma doença crônica e vem crescendo no mundo; logo, o médico precisa, cada vez mais, se preparar para atender aos pacientes oncológicos. Na maioria das vezes, os protocolos de más notícias não são realizados por meio da óptica do paciente. Objetivo: Conhecer o efeito do diagnóstico de câncer para o paciente e a sua sugestão sobre o modo de comunicação do diagnóstico. Método: Estudo qualitativo de narrativas de histórias orais, gravadas e, posteriormente, transcritas, sendo utilizado o método de análise de conteúdo proposto por Laurence Bardin. A amostra foi constituída por 30 pacientes oncológicos de 34 a 88 anos em uma clínica particular de Salvador, BA. Resultados e Discussão: Sobre o efeito do diagnóstico, as categorias extraídas foram: aceitação (53\%), choque/susto (33\%), sofrimento (20\%), medo (2\%), racionalismo (2\%), sendo que o mesmo paciente pode apresentar um ou mais tipos de reaçóes. Categorias selecionadas sobre comunicação diagnóstica: diagnóstico por médico não oncologista $(53,3 \%)$, diagnóstico por não médico (30\%), diagnóstico por médico oncologista $(16,6 \%)$; as subcategorias foram: adequada e inadequada. Fala pessimista foi considerada uma comunicaçáo médica inadequada; enquanto uma postura amiga do médico, adequada. Sobre sugestóes de comunicação diagnóstica, as categorias foram: levando em consideração as características do paciente, modo suave e dando esperança, e junto a um familiar. Conclusáo: A aceitação da doença e o choque/susto foram os efeitos mais prevalentes ao diagnóstico. O que indica neste estudo é que, talvez, os oncologistas são mais preparados a informarem más notícias do que os outros profissionais. Levar em consideração as características do sujeito e dar informação de modo suave, dando esperança, foram as principais sugestôes de comunicação diagnóstica pelos pacientes.

Palavras-chave: Neoplasias; Revelação da Verdade; Narrativas Pessoais; Pesquisa Qualitativa; Psico-Oncologia.

\section{Abstract}

Introduction: Cancer is classified as a chronic disease and has been growing in the world; therefore, the doctor needs, more and more, to prepare to attend cancer patients. Most of the bad news protocols are not performed through the patient's lens. Objective: To know the effect of the diagnosis of cancer for the patient, and his suggestion about the way of communicating the diagnosis. Method: Qualitative study of narratives of oral histories, recorded and later transcribed, using the method of content analysis proposed by Laurence Bardin. The sample consisted of 30 cancer patients aged 34 to 88 years in a private clinic in Salvador, Bahia. Results and Discussion: The categories were: acceptance (53\%), shock/fright $(33 \%)$, suffering $(20 \%)$, fear $(2 \%)$, rationalism $(2 \%)$, patient was able to present one or more types of reactions. Selected categories on diagnostic communication: diagnosis by non-oncologist $(53.3 \%)$, diagnosis by nonphysician (30\%), diagnosis by oncologist (16.6\%), and subcategories were: adequate and inadequate. Pessimistic speech was considered an inadequate medical communication; while an appropriate physician-friendly posture. Conclusion: Acceptance of the disease and shock/fright were the most prevalent effects at diagnosis. Patients with mild to moderate symptoms were considered to be diagnosed. What it indicates in this study is that, perhaps, oncologists are more prepared to report bad news than other professionals. Taking into account the characteristics of the subject and giving information in a gentle manner, giving hope were the main suggestions of diagnostic communication by the patients.

Key words: Neoplasms; Truth Disclosure; Personal Narratives; Qualitative Research; Psycho-Oncology.

\section{Resumen}

Introducción: El cáncer se clasifica como una enfermedad crónica y viene creciendo en el mundo; el médico necesita, cada vez más, prepararse para atender a los pacientes oncológicos. La mayoría de los protocolos de malas noticias no se realiza a través de la óptica del paciente. Objetivo: Conocer el efecto del diagnóstico de cáncer para el paciente, y su sugerencia sobre el modo de comunicación del diagnóstico. Método: Estudio cualitativo de narrativas de historias orales, grabadas y posteriormente transcritas, siendo utilizado el método de análisis de contenido propuesto por Laurence Bardin. La muestra fue constituida por 30 pacientes oncológicos de 34 a 88 años en una clínica particular de Salvador, BA. Resultados y Discusíon: En el caso del diagnóstico, las categorías extraídas fueron: aceptación (53\%), shock/ susto $(33 \%)$, sufrimiento $(20 \%)$, miedo $(2 \%)$, racionalismo $(2 \%)$, siendo que el mismo, el paciente pudo presentar uno o más tipos de reacciones. En la mayoría de los casos, se observó un aumento de la mortalidad por rotavirus en los últimos años. Habla pesimista fue considerada una comunicación médica inadecuada; mientras que una postura amiga del médico, adecuada. En las sugerencias de comunicación diagnóstica, las categorías fueron: tomando en consideración las características del paciente, modo suave y dando esperanza y junto a un familiar Conclusión: La aceptación de la enfermedad y el shock/ susto fueron los efectos más prevalentes al diagnóstico. Lo que indica en este estudio es que, quizás, los oncólogos están más preparados para informar malas noticias que los demás profesionales. Tomar en consideración las características del sujeto y dar información de modo suave, dando esperanza fueron las principales sugerencias de comunicación diagnóstica por los pacientes. Palabras clave: Neoplasias; Revelación de la Verdad; Narrativas Personales; Investigación Cualitativa; Psicooncología.

\footnotetext{
${ }^{1}$ Faculdade de Tecnologia e Ciências (FTC). Salvador (BA), Brasil. Orcid iD: https://orcid.org/0000-0002-7790-3561

${ }^{2}$ Escola Bahiana de Medicina e Saúde Pública. Salvador (BA), Brasil. Orcid iD: https://orcid.org/0000-0001-7797-4530

${ }^{3}$ Instituto do Câncer Arnaldo Vieira de Carvalho. São Paulo (SP), Brasil. Orcid iD: https://orcid.org/0000-0001-6107-5098

${ }^{4}$ FTC. Salvador (BA), Brasil. Orcid iD: https://orcid.org/0000-0002-3596-8711
}

Endereço para correspondência: Alessandra da Cunha Neumayer. Rua do Mangalô, 233 - Salvador (BA), Brasil. CEP 41680-048. E-mail: alessandraneumayer@gmail.com 


\section{INTRODUÇÃO}

O câncer, assim como outras doenças, como o diabetes, as doenças cardiovasculares e renais, é classificado como uma doença crônica; mas, diferentemente das outras doenças, ele remete, aos que escutam a palavra, a cenários, como queda de cabelo, quimioterapia, náusea, vômito, tristeza e hospitalização, visto que já foi timbrada a sua representação negativa na sociedade $e^{1,2}$.

Segundo a Organização Mundial da Saúde (OMS), a incidência do câncer, no mundo, em 2017, foi de mais de 14 milhóes e a sua taxa de mortalidade de 8,8 milhóes $^{3}$. Assim, a sua incidência vem aumentando, estimando-se que, em 2030, no mundo, alcançará mais de 21 milhóes de casos novos ${ }^{3}$.

O câncer tem um potencial invasivo e agressivo, porém há uma evolução constante nos métodos diagnósticos, bem como terapêuticos (quimioterapia, radioterapia, imunoterapia, técnicas cirúrgicas), e um aumento da possibilidade de cura ${ }^{4}$. Além disso, mesmo em diagnósticos em estágios avançados, consegue-se traçar planos reais de boas perspectivas de vida aos pacientes, com aumento de sobrevida e melhora na qualidade de vida ${ }^{4}$.

Diante dessa perspectiva, o médico precisa, cada vez mais, se preparar para atender a pacientes oncológicos e, para isso, conhecer a atmosfera que cerca o doente durante o recebimento do diagnóstico é fundamental para ajudar os doentes nos tratamentos e rotinas oncológicos. Somado a isso, na atualidade, apesar de existirem muitos protocolos de más notícias, entre eles, o mais famoso, o Spikes, a maioria se baseia na opinião dos médicos e não dos seus pacientes ${ }^{5-8}$.

Portanto, como o câncer é uma doença com alta morbidade e mortalidade, e também gerador de forte sofrimento físico e emocional, é de fundamental relevância analisar as questôes existenciais dos pacientes no momento do recebimento da notícia de câncer. Este estudo poderá auxiliar os médicos em como anunciar um diagnóstico tão delicado, tendo em vista a escassez de estudos, na perspectiva do doente. Dessa forma, este trabalho objetiva conhecer o efeito do diagnóstico de câncer para o paciente e a sua sugestão sobre o modo de comunicação do diagnóstico.

\section{MÉTODO}

Estudo qualitativo, de abordagem narrativa, realizado a partir de preenchimento de questionário sociodemográfico e entrevista semiestruturada. Constaram no roteiro das entrevistas perguntas sobre o tipo de câncer, quem informou o diagnóstico, como essa notícia foi recebida, a opinião sobre o modo da comunicação, além de sugestôes para uma melhor comunicação. As narrativas foram registradas por meio de um gravador, transcritas posteriormente de modo fidedigno, e serão guardadas pelas pesquisadoras por cinco anos. As entrevistas duraram de 2 minutos e 57 segundos a 30 minutos e 57 segundos, com uma média 10,19 minutos. Foi realizado um piloto, anteriormente, com duração de 5 minutos e 30 segundos.

A coleta se deu no período de 10 a 21 de julho de 2017, no Núcleo de Oncologia da Bahia (clínica particular e que atende a seguradoras de saúde), em Salvador, a amostra constou de 30 participantes que já tinham prévio conhecimento do seu diagnóstico. Antes de abordá-los, a pesquisadora certificava-se com a equipe sobre o entendimento daqueles pacientes, a entrevista aconteceu no box fechado, onde o paciente recebia quimioterapia, ou no quarto, onde o participante aguardava por algum procedimento. As entrevistas ocorreram em ambiente reservado, a fim de resguardar o sigilo e a privacidade dos pacientes, esta pesquisa foi aprovada pelo Comitê de Ética e Pesquisa (CEP), do Instituto Mantenedor de Ensino Superior da Bahia, da Faculdade de Tecnologia e Ciências (FTC), sob o número de aprovação CAAE: 65633317.9.0000.5032. Foi realizado um contato prévio com os pacientes, rapport, com o intuito de tornar o ambiente mais harmônico?. Foram especificados os objetivos do estudo e explicado e assinado o Termo de Consentimento Livre e Esclarecido (TCLE).

Os pacientes que aceitaram participar do estudo, logo após assinarem o TCLE, responderam ao questionário sociodemográfico e, em seguida, realizou-se a entrevista.

A amostra foi finalizada por saturação, na medida em que se atingiu certa diversidade, abrangência e riqueza dos discursos ${ }^{10}$.

Utilizou-se, como método de análise de dados, a análise de conteúdo proposta por Bardin ${ }^{11}$, que possibilita ao investigador analisar tecnicamente cada detalhe do discurso, o que promove a extração das ideias mais profundas de uma fala.

Iniciou-se a análise com uma "leitura flutuante" de todas as entrevistas transcritas, sem interesse em estabelecer categorias previamente, a fim de buscar uma ideia geral do texto a ser abordado ${ }^{11}$. Após essa leitura, foram codificadas categorias de análise que reuniam os principais pontos de respostas dadas pelos entrevistados. As subcategorias foram criadas após uma leitura mais cartesiana do texto, sendo notados determinados elos nas falas dos entrevistados.

Os participantes tinham idade entre 34 e 88 anos, com média de 61,5 anos e desvio-padrão de 11,22; $66,7 \%$ eram do sexo feminino, $56,7 \%$ brancos, $53,3 \%$ estavam aposentados, $66,6 \%$ tinham ensino superior completo, $66,7 \%$ eram casados, $83,3 \%$ residiam em Salvador e 43,3\% eram católicos. Quanto ao tipo, 26,7\% apresentavam câncer de intestino, 13,3\% de mama, $10 \%$ de pulmão e $10 \%$ no tecido linfoide; $50 \%$ dos participantes descobriram o câncer de 2016 a 2017.

Visando à nâo identificação dos participantes do estudo, foram colocados os primeiros ou os últimos 
nomes de escritores da literatura ou filosofia nas amostras e também o tipo de câncer.

\section{RESULTADOS E DISCUSSÃO}

Os eixos da entrevista semiestruturada foram o efeito do recebimento da notícia, o tipo de comunicação diagnóstica e as sugestóes para a melhoria da comunicação diagnóstica. A partir da análise, categorias e subcategorias foram selecionadas para responder aos objetivos deste estudo. Alguns trechos das narrativas dos participantes serão citados, exemplificando o conteúdo das categorias.

\section{EIXO DA NARRATIVA: EFEITO DO RECEBIMENTO DA NOTÍCIA}

A partir desse tópico, surgiram as categorias aceitação, susto/choque, sofrimento, medo e racionalismo. Após o recebimento da notícia, a maioria dos participantes (53\%) aceitou o diagnóstico, muitos sentiram-se assustados (33\%), alguns revelaram sofrimento $(20 \%)$ e poucos mostraram medo (2\%) ou racionalismo (2\%). Reitera-se que o mesmo paciente pode apresentar um ou mais efeitos de recebimento da notícia.

\section{Categoria: Aceitação}

A aceitação apareceu nas perspectivas de que o câncer pode chegar para qualquer um, da ausência do medo da morte e de encarar o câncer como uma doença como outra qualquer.

[...] eu digo sempre que eu não sou nem pior do que os outros nem diferente. Então, isso pode chegar na porta do vizinho, como chegou para mim, né? (Gertrude, linfoma).

[...] eu nunca tive medo de morrer, já nessa minha idade, a única coisa que eu ficaria pedindo a Deus é que me desse mais um tempo por causa das minhas netas [...] (Gregório, linfoma).

Ao não se achar melhor do que ninguém, Gertrude remete a sua aceitação à ideia de que todo o ser humano é vulnerável, falível, inclusive, no cenário de saúde ${ }^{12}$.

Por meio do filósofo Sêneca, imortalizado por sua frase "viver é aprender a morrer", pode-se considerar a consciência da finitude como um árduo aprendizado, condição que pode ter ajudado Gregório a aceitar o seu diagnóstico ${ }^{12}$.

O estudo de $S_{0 u z a}{ }^{13}$, com pacientes com variados tipos de cânceres, encontrou, como principais respostas, o choque e a aceitação ao diagnóstico. Estudo com pacientes com câncer de pulmão, no Reino Unido, teve como reaçóes mais frequentes ao diagnóstico o choque e a resignação (aceitação) ${ }^{14}$.

\section{Categoria: Susto/Choque}

A surpresa se manifestou nos participantes como reação ao que não era esperado.

[...] eu tomei um susto [...]. Realmente, foi uma surpresa grande, eu tinha certeza de que ia dar negativo [...] (Clarice, útero).

Um choque, uma surpresa, porque a gente acha que não vai acontecer com a gente, pelo menos, sempre me senti muito saudável (Jane, mama e útero, não metastático).

Ao reagirem com surpresa ao diagnóstico, entende-se que os pacientes deste estudo não estavam preparados para a possibilidade de um diagnóstico de câncer.

Estudo na Suécia teve o choque como palavra mais presente ao recebimento do diagnóstico ${ }^{15}$. Estudo australiano, com pacientes com cânceres de mama ou melanoma, teve como principais reaçóes ao diagnóstico o choque e susto, seguidos de aceitação e tristeza ${ }^{16}$.

\section{Categoria: Sofrimento}

O sofrimento foi atrelado, metaforicamente, como dor.

[...] a notícia do câncer, você imagina, mas você não pode sentir, nem eu quero que as pessoas sintam, é uma dor que dói, é a dor que dói (Florbela, figado).

O sofrimento relatado por Florbela sobre o diagnóstico como uma “dor que dói”, pode ser em razáo da sua possível ideia de câncer como imagem de dor e morte. Segundo Pelaez Dóro et al. ${ }^{17}$, isso condiz com uma profecia autoelaborada que, em vez de o paciente conseguir aceitar o processo e realizar o enfrentamento, se inclina para a maximização das dificuldades.

\section{Categoria: Medo}

[...] muito medo, sem chão [...]. Eu sentei no banquinho do jardim do Hospital para abrir o exame e eu fiquei olhando para aquilo e pensando: “o que será daqui para frente?” [...] (Cecília, ovário).

Por meio de sua fala, Cecília mostra um temor não só ao futuro, mas ao futuro com câncer; portanto, pode-se atribuir a isso a construção social negativa do câncer adquirida pela paciente.

Estudo norueguês observou que o medo se fez mais presente no momento da suspeita do diagnóstico até a sua confirmação e nos períodos em que o paciente já tratado iria realizar exames rotineiros de reavaliação, o que gerava o medo da recidiva ${ }^{18}$. 


\section{Categoria: Racionalismo}

O racionalismo apareceu como um agente antecipatório ao diagnóstico de câncer.

Foi recebida de uma forma de quem já esperava, porque eu fumei durante 55 anos e, quando esse nódulo apareceu, eu já tinha outras complicaçóes no pulmáo. Então, a partir daí, o próximo que poderia vir seria um câncer mesmo [...] (Gabriel, pulmáo).

Ao Gabriel revelar que já esperava o diagnóstico de câncer, mesmo antes de o médico lhe passar a notícia, ele fez uso do racionalismo proposto por Descarte ${ }^{19}$ no século XVI. No caso, Gabriel utilizou a correlação científica do tabagismo ao surgimento do câncer de pulmão para justificar o seu diagnóstico.

\section{EIXO DA NARRATIVA:TIPO DE COMUNICAÇÃO DIAGNÓSTICA}

Sobre o tipo de comunicação diagnóstica, surgiram as categorias: comunicação por médico não oncologista, 53,3\%; comunicação por não médico, 30,0\%; comunicação por médico oncologista, 16,6\%.

\section{Categoria: Comunicação por médico não oncologista}

Sobre essa categoria, surgiram as subcategorias: adequada e inadequada. Dos pacientes que receberam o diagnóstico por médico não oncologista, 56,25\% consideraram a comunicação adequada, enquanto $43,75 \%$, inadequada.

\section{Subcategoria: Adequada}

Os pacientes consideraram como adequada uma comunicação feita com uma fala clara e tranquila. $\mathrm{O}$ estabelecimento de amizade, o cuidado, o carinho e o conhecimento demonstrado pelo médico também foram considerados positivos.

A médica foi até bem calma, tranquila [...]. Ela foi bem amiga, controlando também para ver minha reação [...] (Virginia, intestino).

O médico foi muito cuidadoso, foi uma pessoa muito especial, fez questão de falar pessoalmente. Ele foi pegar o resultado da biópsia no laboratório, então, como ele quis dar pessoalmente o resultado, eu já achei que não era uma coisa boa. E aí, pela própria expressão dele, eu vi [...], ele foi muito cuidadoso, muito carinhoso (Zélia, linfoma).

A médica é uma pessoa muito humana e de um potencial espiritual muito grande, entáo, ela me falou francamente [...] eu achei que a médica me ajudou muito, a forma como ela me disse, porque ela foi muito sincera e muito capaz. Ela demonstrou que tinha conhecimento do que estava fazendo [...] achei que foi adequada a forma humana como ela se relacionou comigo (Simone, mieloma múltiplo).

Os discursos anteriores demonstram que o médico não foi apenas um informante sobre o estado de saúde dessas pessoas, mas criou uma relaçáo com elas. $\mathrm{O}$ estabelecimento de uma relação, do ponto de vista cognitivo, traz uma ideia de continuidade, de ordem, de confiança e isso ameniza a desordem que a doença, inconscientemente, provoca no indivíduo ${ }^{15}$.

\section{Subcategoria: Inadequada}

Consideraram-se atitudes inadequadas, na comunicaçáo diagnóstica, associar o câncer à realidade de que todos váo morrer um dia, a falta de sensibilidade do médico e o não fornecimento de esperança.

[...] ele disse assim "todo mundo vai morrer um dia", foi do jeito que ele me disse, aí eu não gostei, porque eu achei que ele foi muito grosseiro. Ele quis dizer que eu não tinha mais cura, não é? [...] (Lewis, pulmão).

Eu achei péssima, esse médico neurologista só me dava más notícias. Não me lembro de ele ter me dado nenhuma boa notícia. Toda vez que ele entrava no meu quarto, ele só chegava para me dar má notícia. Quando ele chegava na porta do quarto, eu já via logo "alguma coisa vem aî" [...], sinceramente, eu acho que ele precisava ser melhor preparado, porque para dar uma notícia do jeito que ele chegava "ah, olhe, é maligno, viu?", só chegava para me dar má notícia. Eu, sinceramente, jamais ficaria com um profissional daquele. Eu achei que ele não estava preparado para conduzir esse tipo de coisa (Baudelaire, cérebro).

Frio, muito frio. Ele começou a fazer um desenho e chamou o meu marido, começou a desenhar e [...] depois disse que era um câncer [...] (Cora, intestino).

Outros estudos mostraram que os pacientes sentiram uma atitude pessimista do médico, não passando esperança e nem abordando pontos positivos referentes ao tratamento ${ }^{15,18,20}$. Esse direcionamento do diagnóstico médico, sem focar nos pontos positivos, foi narrado pelos pacientes acima.

O diagnóstico de câncer dado em poucas palavras e sem qualquer foco na pessoa que recebe a notícia pode ser experimentado como desumano e humilhante ${ }^{18}$.

A narrativa de Cora mostra que o excesso de informaçôes, passadas pelo médico, não teve um efeito positivo. Essa desaprovação também esteve presente no estudo de Salander ${ }^{15}$, visto que os participantes não gostaram quando 
o médico explicou com riqueza de detalhes as informaçóes sobre as suas doenças, sendo considerados sádicos. Essa postura do médico focar mais nas informaçóes do que na relação com o paciente, no momento da notícia do câncer, parece ser um fator confortável para o profissional, na medida em que usa a ciência como um escudo, um velamento a possíveis emoçôes negativas.

\section{Categoria: Comunicação por não médico}

Trinta por cento dos pacientes souberam do diagnóstico sem intermédio do médico. Dos pacientes que souberam do diagnóstico sem intermédio de um médico, houve os que souberam sozinhos, $77,77 \%$, por meio da leitura do próprio exame complementar; e os que receberam a notícia por familiares, $22,22 \%$.

\section{Categoria: Diagnóstico pela leitura do próprio exame}

A maioria dos pacientes nessa categoria $(57,14 \%)$ considerou essa forma de recebimento da notícia inadequada, enquanto $42,85 \%$ consideraram adequada.

\section{Subcategoria: Inadequada}

A ausência da médica foi um fator negativo para Dorothy.

[...] como eu fui fazer o exame em outro estado, eu nấo tinha como ir pegar esse resultado. Tive que pedir para eles mandarem [...]. E aí, não foi fácil, porque acho que você ouvindo da sua médica, ela vai lhe orientar direitinho [...] não foi bom o resultado dessa forma, não foi legal (Dorothy, mama).

\section{Subcategoria: Adequada}

O antigo paternalismo médico está sendo substituído por uma Medicina que respeita a autonomia do paciente, e muitos médicos estáo, cada vez mais, preocupados em situar o paciente como membro ativo da sua saúde ${ }^{21}$.

[...] eu gostei de estar sozinha naquele momento. Eu prefiro ler e depois ir perguntar [...] no meu caso, eu prefiro tomar a porrada sozinha e depois dividir (Clarice, útero).

Fantástico, porque eu sou muito autônoma, as coisas que me dizem respeito, eu gosto de decidir. Não fui com medo, não fiquei receosa, fui, peguei e abri [...]. Saí de lá, liguei para o mastologista, que tinha me aconselhado 1 ano antes e aí ele falou assim "onde é que você está?", eu falei "estou aqui no laboratório". Ele falou assim, "venha aqui” [...] (Hilda, mama).

\section{Categoria: Diagnóstico por meio de familiares}

Dois participantes receberam a notícia por familiares ou amigos, sendo que um considerou adequada e o outro inadequada a forma de recebimento do diagnóstico.

\section{Subcategoria: Adequada}

A condiçáo de ter um agente, familiar ou amigo, intermediário na comunicaçáo médica, funcionou como um crivo, só sendo passadas informaçôes consideradas pertinentes ao paciente, sendo considerada adequada por Balzac.

Eu soube por intermédio de alguém, eu não fui me dedicar aquilo a fundo, porque ficava chato para mim, porque a pessoa está doente e ficar encafifado que está doente é problema mais ainda (Balzac, figado).

De acordo com Pereira ${ }^{21}$, é relativamente comum, no contexto brasileiro, a família pedir ao médico para que o paciente não seja informado sobre o seu diagnóstico. $\mathrm{O}$ ideal, entretanto, é que o médico converse com a família julgando os benefícios da divulgação do diagnóstico e os malefícios da omissão ${ }^{21}$. A família de Balzac não resolveu esconder-lhe o diagnóstico, mas esperou o momento apropriado para informá-lo.

\section{Subcategoria: Inadequada}

Outro paciente considerou inadequado o médico ter informado o diagnóstico primeiramente a uma amiga, percebendo que informaçôes lhe foram omitidas:

Inicialmente, o médico não passou para mim, passou para uma amiga nossa que nos acompanhava, aí depois comentaram comigo. Eu acho que não tem que esconder, na minha opinião, não tem que esconder nada de ninguém (Gregório, linfoma).

Estudo, no Japão, descobriu que os pacientes que não foram informados do diagnóstico de câncer experimentaram sofrimento mais grave do que aqueles que foram informados ${ }^{22}$.

\section{Categoria: Comunicação por médico oncologista}

Um total de 16,6\% dos pacientes recebeu o diagnóstico por um médico oncologista. Todos os pacientes que receberam o diagnóstico por esses profissionais consideraram adequada a forma de recebimento da notícia.

Considerou-se uma comunicaçáo adequada um diálogo por etapas, no qual a médica percebe as reaçóes da paciente para ir adiante nas informaçóes.

Gostei porque a médica não deu assim, sabe? Porque se desse assim, acho que, risos. Ela foi dando, explicando, conversando, aí eu fui absorvendo mais, né? Se dissesse logo no impacto, eu náo sei o que seria (Rachel, intestino).

Estudo brasileiro com pacientes oncológicos e seus familiares revelou que $87,9 \%$ dos médicos não especialistas omitiram a notícia de câncer ao paciente, enquanto 
apenas $6,4 \%$ dos oncologistas omitiram o diagnóstico ${ }^{23}$. Isso parece sugerir que a especialidade oncológica prepara mais os médicos para abordarem as más notícias do que as outras especialidades.

Situação essa que merece destaque; pois, apesar dessa preparação do oncologista, em muitos casos, não é ele quem dá o diagnóstico inicial de câncer ao doente. $\mathrm{O}$ médico generalista, principalmente no Sistema Único de Saúde (SUS), pode ser o primeiro a ter contato com esse paciente e o primeiro a encaminhá-lo ao oncologista, então, a familiaridade aos protocolos, temas e discussóes sobre más notícias deveria ser uma demanda de todas as especialidades médicas.

\section{EIXO DA NARRATIVA: SUGESTÕES PARA A MELHORIA DA COMUNICAÇÃO DIAGNÓSTICA}

A partir das sugestôes dadas pelos participantes deste estudo, selecionaram-se as categorias: comunicação levando em conta as características do paciente; comunicação diagnóstica de modo suave, dando esperança; e comunicação diagnóstica junto a um familiar.

Dos pacientes que deram sugestôes acerca da melhor forma de dar o diagnóstico de câncer, 50\% falaram que o médico deve levar em consideraçáo as características emocionais do paciente; $35,71 \%$ falaram que o médico deve dar a notícia de forma suave, dando esperança; e $14,2 \%$ sugeriram que o diagnóstico deve ser dado junto a um familiar. Reitera-se que o mesmo paciente pode dar uma ou mais sugestóes.

Apesar de existirem muitos protocolos de más notícias, geralmente, tais documentos são feitos com base na opinião do médico e não do paciente $5,9,15,16,22,24,25$.

As diretrizes devem ser derivadas de dados baseados em pacientes ao invés da opinião dos médicos ${ }^{16,20,22}$.

O protocolo Spikes foi criado por Robert Buckman em 1992. Trata-se de um mnemônico, em inglês, cujo "S" significa setting up the interview - configurando ou organizando a entrevista - em que o médico repassa mentalmente as informaçóes que serâo ditas ao paciente e reserva um ambiente adequado; "P" (perception - percepçáo), momento de descobrir o grau de conhecimento que o paciente tem do seu estado atual; "I" (invitation - convite), hora de saber se o seu paciente gostaria de ter conhecimento sobre o seu diagnóstico; "K" (knowledge-conhecimento), esse é o momento da notícia, primeiramente pode-se iniciar a fala com "infelizmente, não temos boas notícias" sendo fornecida em termos compreensíveis, gradativamente, evitando-se citar palavras muito duras; "E" (emotions - emoçóes), o profissional deve tentar interpretar as emoçóes do paciente e mostrar preocupação; "S" (strategy and summary - estratégia e resumo), hora de traçar um plano de metas juntamente com o paciente, sempre questionando a vontade do paciente, compartilhando as responsabilidades ${ }^{5,7,8}$.
Ao analisar o protocolo Spikes, de acordo com estudos envolvendo a percepção dos pacientes, sobre o momento "S", não foram levantadas queixas sobre o local e a privacidade, talvez esses aspectos tenham sido garantidos pelos médicos; mostra-se também muito pertinente o convite do acompanhante nesse momento ${ }^{15,16,22,26}$.

Os estágios "P" e "I" são muito relevantes, visto que a maioria dos participantes deste estudo e de outras pesquisas defende que o diagnóstico deve ser dado de acordo com as condiçóes individuais dos sujeitos ${ }^{13-16,22,24}$.

Sobre a etapa "K", os pacientes oncológicos de um estudo revelaram que não gostam quando o médico inicia a frase com pessimismo, como "infelizmente" ou "sinto muito"15. Além disso, os pacientes ressaltam a importância de o médico transmitir a notícia de forma suave ${ }^{13,14,22}$. Estudos também mostram que o médico deve dar o diagnóstico de forma clara, compreensível ao paciente ${ }^{14,22,24,27}$.

Em relação à etapa "E", os pacientes relatam a necessidade de o médico não sair da sala e deixá-los sozinhos após a reação ao diagnóstico ${ }^{27}$. Em alguns casos, os médicos chamam outros profissionais para ajudá-lo; nesse momento, no entanto, muitos pacientes não acham necessária a presença de outros profissionais não médicos no instante da notícia ${ }^{15,16,21,26}$.

$\mathrm{O}$ último estágio " $\mathrm{S}$ " é talvez o mais difícil para os médicos, pois eles podem ter receio de passar falsas expectativas ao doente. No entanto, os pacientes, em estudos, apontam a importância de o profissional passar esperança no momento do diagnóstico ${ }^{13-15,18,22}$. Os pacientes reiteram que a esperança poderia ser depositada nas questóes referentes ao tratamento ao invés de o profissional focar nas questóes relacionadas à doença ${ }^{14,18,22,24}$. Dar o diagnóstico, aos poucos, de forma suave, também foi sugerido por estudos que abarcaram a opinião dos pacientes ${ }^{14,22,24}$.

\section{Categoria: Comunicação levando em conta as características do paciente}

Os participantes consideraram que o diagnóstico deve ser dado pelo médico de acordo com os traços emocionais.

Eu acho que depende muito do paciente, depende mais do paciente do que do médico. Tem pacientes que são muito emotivos, e existem pacientes que são muito realistas e existem pacientes que são muito religiosos (Gabriel, pulmão).

[...] eu conversaria com o paciente para saber se ele tem capacidade de receber essa notícia, porque, às vezes, o paciente não está preparado, e não tem noção da coisa [...] (Agatha, intestino).

Os médicos, ao darem o diagnóstico de câncer, precisam prestar um olhar diferenciado ao paciente, reconhecendo mecanismos de enfrentamento individuais ${ }^{14}$. 


\section{Categoria: Comunicação diagnóstica de modo suave, dando esperança}

A esperança foi levantada no sentido de vencer a doença, no sucesso do tratamento.

Tem que dizer de uma forma suave e dando esperança: "Olha, você pode vencer". É a melhor maneira (Marguerite, intestino).

Eu acho que a melhor maneira de dizer isso talvez esteja relacionada à possibilidade de afirmar a perspectiva de sucesso no tratamento [...] é importante dar a esse paciente uma energia [...] (Manuel, timo).

De acordo com Salander ${ }^{15}$, os pacientes do seu estudo sentiram a necessidade de o médico, ao dar o diagnóstico de câncer, focar nas possibilidades do tratamento, o que proporciona um sentido de esperança ao doente. No presente estudo, Manuel também se referiu à esperança no sentido do tratamento.

$\mathrm{Na}$ visão de Marguerite, o médico, ao anunciar a notícia do câncer, deve fornecer esperança ao paciente. Sabe-se, contudo, que, em muitos casos, o prognóstico da doença pode ser sombrio; assim, o profissional tende a ser receoso ao transmitir sentimentos encorajadores aos seus pacientes ${ }^{7}$. Entretanto, mesmo quando o paciente náo tem chance real de cura, o médico não deve retirar as esperanças do indivíduo, pois sempre há um plano a ser traçado como, por exemplo, estratégia de controle da dor ${ }^{7,8}$.

\section{Categoria: Comunicação diagnóstica junto a um familiar}

A companhia da família, no momento da notícia do câncer, foi sugerida como suporte emocional.

O que eu acho mais importante é que tenha sempre alguém, que você nunca vá só, porque eu, nesse momento, que recebi esse resultado, se náo fosse o suporte de meu marido [...], não sei do que seria capaz [...] (Dorothy, mama).

O familiar, no momento do diagnóstico, parece ter um efeito amortecedor, na medida em que compartilha as emoções vividas pelo paciente ${ }^{28-30}$. Fato esse que foi relatado por Dorothy.

\section{CONCLUSÃO}

Os principais efeitos do diagnóstico de câncer, vivenciados pelos pacientes deste estudo, foram a aceitação da doença e o susto/choque à nova realidade. Em relação ao tipo de comunicação diagnóstica, dos pacientes que receberam o diagnóstico pelos médicos não oncologistas, a maioria considerou adequada a comunicação, revelando que uma postura amiga do médico estabelecedora de vínculo e humana se mostraram assertivas. Enquanto uma fala pessimista, fria e rica de informações médicas foi considerada inadequada. As formas de diagnóstico não médicas neste estudo foram o recebimento do diagnóstico pela leitura do exame e por familiares ou amigos. Dos pacientes que receberam o diagnóstico pela leitura do próprio exame, a maioria achou inadequada essa forma de comunicação, enquanto para os que receberam a notícia pelos familiares ou amigos, um paciente achou adequada e o outro inadequada. Todos os pacientes deste estudo que receberam o diagnóstico de câncer pelo médico oncologista ficaram satisfeitos com o modo de recebimento da notícia, o que pode ser o reflexo de uma melhor preparaçáo e experiência desses profissionais na comunicação de más notícias. Esse acesso aos temas e a protocolos de más notícias deveria ser uma demanda crescente para as demais especialidades médicas; pois, em muitos casos, os pacientes são encaminhados para o serviço de oncologia com o diagnóstico feito por médicos não oncologistas.

Primeiramente, sobre a óptica dos pacientes oncológicos deste estudo, por intermédio de suas narrativas acerca da sugestão de melhorias da comunicação diagnóstica, a maioria dos participantes defendeu que o médico deve dar o diagnóstico de câncer levando em consideração as características de cada paciente, o que remete à máxima do "primum non nocere"; em segundo lugar, os pacientes defenderam que o médico deve dar o diagnóstico de modo suave e dando esperança; e, em terceiro, sugeriram que o diagnóstico deve ser dado pelo médico junto a um familiar.

\section{CONTRIBUIÇÕES}

Alessandra da Cunha Neumayer, Márcia Cristina Maciel de Aguiar e Eldsamira da Silva Mascarenhas Schettini Sobrinho colaboraram na concepção e planejamento do projeto de pesquisa, na obtenção e/ou análise e interpretação dos dados e na redação e revisão crítica. Alinne Santiago Ramos Gonçalves colaborou na redação e revisão crítica. Todos os autores aprovaram a versão final do manuscrito.

\section{DECLARAÇÃO DE CONFLITO DE INTERESSES}

Nada a declarar.

\section{FONTES DE FINANCIAMENTO}

Não há.

\section{REFERÊNCIAS}

1. Barbosa LNF, Francisco AL. A subjetividade do câncer na cultura: implicaçôes na clínica contemporânea. Rev SBPH. 2007 Jun;10(1): 9-24. 
2. Neves MMAMC. A representação social do cancro: conhecer para (re)pensar a intervenção educativa [dissertação]. [Portugal]:Instituto de Ciências Biomédicas de Abel Salazar, Universidade do Porto; 2002. 220 p.

3. Naçóes Unidas. OMS: câncer mata 8,8 milhóes de pessoas anualmente no mundo [Internet]. [Brasília]: ONUBR; 2017 Fev 03 [acesso 2018 Jun 17]. Disponível em: https://nacoesunidas.org/oms-cancer-mata-88milhoes-de-pessoas-anualmente-no-mundo/.

4. Medicina personalizada, terapia alvo, quimioterapia - o que tudo isso significa em oncologia de precisão? [Internet]. São Paulo: Instituto Oncoguia; 2015 Fev 27 [acesso 2018 Abr 1]. Disponível em: http://www.oncoguia.org.br/conteudo/medicinapersonalizada/7207/840/.

5. Neto Chehuen JA, Sirimarco MT, Cândido TC, Bicalho TC, Matos BO, Berbert GH, et al. Profissionais de saúde e a comunicação de más notícias sob a ótica do paciente. Rev Med Minas Gerais. 2013;23(4):518-25. doi: https://dx.doi.org/10.5935/2238-3182.20130079.

6. Lino CA, Augusto KL, Oliveira RAS, Feitosa LB, Caprara A. Uso do protocolo Spikes no ensino de habilidades em transmissão de más notícias. Rev Bras Educ Med. 2011 Jan/Mar;35(1):52-57. doi: http:// dx.doi.org/10.1590/S0100-55022011000100008.

7. Baile WF, Buckman R, Lenzi R, Glober G, Beale EA, Kudelka AP. SPIKES - Um protocolo em seis etapas para transmitir más notícias: aplicação ao paciente com câncer. The Oncologist [Internet]. 2000 [acesso 2018 Janeiro 26];5:302-311. Disponível em: https://edisciplinas. usp.br/pluginfile.php $/ 4356704 / \mathrm{mod}$ _folder/content $/ 0 /$ SPIKES\%20\%E2\%80\%93\%20Um\%20Protocolo\%20 em $\% 20$ Seis $\% 20$ Etapas\%20para\%20Transmitir\%20 M \% C 3\% A 1 s \% 20 N o t \% C 3\% A D c i a s \% 20 Aplica $\%$ C3\%A7\%C3\%A3o\%20ao\%20Paciente\%20co.pdf?forcedownload $=1$.

8. Cruz CO, Riera R. Comunicando más notícias: o protocolo Spikes. Diagn Trat.2016;21(3):106-108.

9. Oliveira MF. Entrevista psicológica - o caminho para aceder o outro [monografia]. Porto: Universidade Lusíada do Porto; 2005. 37 p.

10. Minayo MCS. Amostragem e saturação em pesquisa qualitativa: consensos e controvérsias. RPQ. 2017 Abr;5(7):01-12.

11. Bardin L. Análise de Conteúdo. São Paulo: Ediçôes 70; 2016.

12. Schramm FR. Morte e finitude em nossa sociedade: implicaçóes no ensino dos cuidados paliativos. Rev Bras Cancerol. 2002 Jan-Mar;48(1):17-20.

13. Souza LH. Percepçóes de pacientes com câncer quanto ao conhecimento e revelação deste diagnóstico [Monografia]. Florianópolis: Universidade Federal de Santa Catarina; 2004. 29 p.
14. Yardley SJ, Davis CL, HM, Sheldon SF. Receiving a diagnosis of lung cancer: patients' interpretations, perceptions and perspectives. Palliat Med. 2001;15(5):379-386. doi: https://doi. org/10.1191/026921601680419429.

15. Salander P. Bad news from the patient's perspective: an analysis of the written narratives of newly diagnosed cancer patients. Soc Sci Med. 2002 Set;55(5):721-732.

16. Butow PN, Kazemi JN, Beeney LJ, Griffin AM, Dunn SM, Tattersall MHN. When the diagnosis is cancer: patient communication experiences and preferences. Cancer. 1996 June;77(12):26302637. doi: https://doi.org/10.1002/(SICI)1097$0142(19960615) 77: 12<2630$ : : A I D CNCR29>3.0.CO;2-S.

17. Pelaez Dóro M, Pasquin R, Medeiros CR, Bitencounrt MA, Moura GL. O câncer e sua representação simbólica. Psicol Cienc Prof. 2004;24(2)120-133. doi: http:// dx.doi.org/10.1590/S1414-98932004000200013.

18. Saegrov S, Halding AG. What is it like living with the diagnosis of cancer? Eur J Cancer Care. 2004 May;13(2):145-153. doi: https://doi.org/10.1111/ j.1365-2354.2004.00442.x.

19. Descartes R. Discurso do Método: meditaçóes. 2 ed. São Paulo: Martin Claret; 2016.

20. Dhage AS, Wilkinson AR. Breaking bad news of cancer diagnosis - the patient's perspective. IJRMS. 2017 April;5(4):1617-21. doi: http://dx.doi. org/10.18203/2320-6012.ijrms20171275.

21. Pereira CR. Comunicando Más Notícias: protocolo PACIENTE. [Tese]. Botucatu: Universidade Estadual Paulista; 2010. 100 p.

22. Fujimori M, Akechi T, Akizuki N, Okamura M, Oba A, Sakano Y, et al. Good communication with patients receiving bad news about cancer in Japan. PsychoOncology. 2005 Dec;14(12):1043-1051. doi: https:// doi.org/10.1002/pon.917.

23. Gomes CHR, Silva PV, Mota FF. Comunicação do diagnóstico de câncer: análise do comportamento médico. Rev Bras Cancerol. 2009;55(2):139-143.

24. Schofield PE, Butow PN, Thompson JF, Tattersall MHN, Beeney LJ, Dunn SM. De. Psychological responses of patients receiving a diagnosis of cancer. Ann Oncol. 2003;14(1): 48-56. doi: https://doi. org/10.1093/annonc/mdg010.

25. Figg WD, Smith EK, Price DK, English BC, Thurman PW, Steinberg SM, et al. Disclosing a diagnosis of cancer: where and how does it occur? J Clin Oncol. 2010 Aug; 28(22): 3630-35. doi: https://doi.org/10.1200/ JCO.2009.24.6389.

26. Gonçalves F, Marques A, Rocha S, Leitão P, Mesquita T, Moutinho S. Breaking bad news: experiences and preferences of advanced cancer patients at a Portuguese 
oncology centre. Palliat Med. 2005 Oct;19(7):526-31. doi: https://doi.org/10.1191/0269216305pm1070oa.

27. Graner KM, Rolim GS, Moraes ABA, Padovani CR, Lopes MA, Santos-Silva AR, et al. Feelings, perceptions, and expectations of patients during the process of oral cancer diagnosis. Support Care Cancer. 2016 Nov; 24(5):2323-32. doi: https://doi.org/10.1007/s00520015-3030-0.

28. Ferreira NML, Dupas G, Costa DB, Sanches KOL. Câncer e família: compreendendo os significados simbólicos. Cienc Cuid Saude. 2010 Abr-Jun; 9(2):269277. doi: https://doi.org/10.4025/cienccuidsaude. v9i2.8749

29. Souza MGG, Santo FHE. O olhar que olha o outro...: um estudo com familiares de pessoas em quimioterapia antineoplásica. Rev Bras Cancerol. 2008;54(1):31-41.

30. Carvalho CSU. A necessária atenção à família do paciente oncológico. Rev Bras Cancerol. 2008;54(1):97-102. 